\title{
Review Achievements Problems: A 70-Year History of the Development of Compulsory Education for the Disabled in China
}

\author{
Zhenzhou Wang1,2 \\ ${ }^{1}$ College of Special Education, Leshan Normal University, Leshan, China \\ ${ }^{2}$ Institute of Education Science, Wuhan University, Wuhan, China \\ Email: zzwang0618@126.com
}

How to cite this paper: Wang, Z. Z. (2020). Review Achievements Problems: A 70-Year History of the Development of Compulsory Education for the Disabled in China. Open Journal of Social Sciences, 8, 239-250.

https://doi.org/10.4236/jss.2020.83022

Received: December 30, 2019

Accepted: March 17, 2020

Published: March 20, 2020

\begin{abstract}
Since the founding of the People's Republic of China in 1949, the reform and development of China's compulsory education for the disabled have gone through the following stages during 70years, there are: Pioneering development of China's compulsory education for the disabled (1949-1978); Constructive development of compulsory education for the disabled in China (1979-2011); Transforming and upgrading China's compulsory education for the disabled (2012-2019). There were full of twists and turns, but at each stage there was remarkable progress. Since the 18th National Congress of the Communist Party of China (CPC), China's compulsory education for the disabled has developed rapidly. Significant increase in compulsory education enrollment for persons with disabilities. However, the development of compulsory education for the disabled exists some problems, such as unbalanced development and low quality of education.
\end{abstract}

\section{Keywords}

Compulsory Education for the Disabled, Access to Educational Right, Examine the Status Quo

\section{Historical Review}

\subsection{Pioneering the Development of Education for the Disabled in China (1949-1978)}

Before the founding of the People's Republic of China in 1949, there were only 42 schools for the blind, the deaf, and schools for the blind and the deaf. After the founding of the People's Republic of China, the development of education 
for the disabled was incorporated into the national development plan and supported by policies and finance, which promoted the development of education for the disabled.

In the 1950s, the state began to take charge of the original schools for the blind and the deaf, and reform them. By the end of the 1950s, schools for the blind and the deaf had been turned into public schools. Before the founding of the People's Republic of China, the education for the disabled was essentially a social relief. During the reform process, part of the education and parenting institutes were changed into public social welfare, so the nature of education in schools has not been clear, civil affairs and education departments in school management also have unclear boundaries. In response to this situation, the council of government made a clear division of labor in 1954, separating schools for the blind and the deaf from welfare institutions, which meant that the nature of education in schools for the blind and the deaf was clarified. Among them, "Decision on Reforming the Academic System" issued by the council of government in 1951 proposed that "people's governments at all levels should establish special schools for youth and adults with deaf, the blind, and physical defects." This marks education for the Disabled was formally included in the national education, and became a landmark event. After a period of adjustment and development, there were 476 schools for the blind, the deaf and the dumb in 1960. At the same time, in order to further promote the development of schools for the blind and the deaf, "Some Instructions for Running Schools for the Blind and Deaf" was issued by Ministry of Education in 1957, standardizing the schooling system, teaching and other aspects, trying to guide the development of schools for the blind and the deaf to a new socialist school. Under the leadership of the CPC, education for the disabled has achieved leapfrog development for only ten years, enabling more and more disabled students to enter schools for education, laying a solid foundation for the development of education for the disabled in the future.

Although the education for the disabled in this period had made remarkable achievements, due to the economic conditions and other factors, such as the shortage of teachers and the low professional quality, which resulted in the low quality of education, and the school buildings were generally hidden security risks. The state has again adjusted schools for the blind, the deaf and the dumb, closed down schools that do not meet the conditions for running schools, and adopted muti-channel training of teachers and widened the sources of funds. By 1965 , the number of schools for the blind and deaf had been increased to 266 , with more than 22,900 students and 2613 full-time teachers. In 1975, China signed the Convention on the Rights of Persons with Disabilities, which recognized the equal rights of persons with disabilities and boosted the development of education for persons with disabilities in China. In the same year, the number of schools for the blind and deaf decreased to 246, with more than 26,800 students and 3445 full-time teachers, showing a certain trend of recovery. Since 1976, various undertakings have been rebuilt and restored, and the state has set 
up special institutions and personnel to manage the education of persons with disabilities.

Overall, education for the disabled in China has gone through the development and bottlenecks at this stage, which shows that it is developing in twists and turns. Although there are some problems that have not been solved, great achievements have been made. For example, education for the disabled should be incorporated into the national educational system, schools for the blind and the deaf should be built, and teachers should be trained. Various measures have been taken to promote the transformation of education for the disabled in China from scratch, highlighting the protection of the rights and interests of the disabled by the CPC and the state.

\subsection{Constructive Development of Education for the Disabled in China (1979-2011)}

During this period, China's education for the disabled has been systematically constructed, involving teachers, curriculum, finance, regulations and other aspects. The system structure of education for the disabled has been enriched and improved through order restoration, active exploration and extension of adjustment, thus releasing new development drivers and promoting the sustained and rapid development of education for the disabled. Among them, the early stage of the pursuit of educational scale has changed to the consideration of fairness in the later stage obviously, which reveals the CPC and the state's humanistic concern tendency increasingly.

At the beginning of the Reform and Opening-up, it became the focus of education for the disabled to promote the "restoration of education order" with the mandatory and guiding of law. The constitution of the People's Republic of China, as amended in 1982, stipulates that "the state and society shall assist in arranging the labor, life and education of blind, deaf, dumb and other citizens with disabilities". It was rare in the world at that time for the education of the disabled to be included in the state's fundamental law. The law of the People's Republic of China on compulsory education promulgated in 1986 clearly stipulates that "local people's governments at various levels shall set up special education schools (classes) for blind, deaf and mentally retarded children and adolescents". This provision further protects the right of students with disabilities to education, and broadens the scope of education object from view of the law, from the original blind, deaf-mute two categories to include the mentally retarded. The two key laws not only strongly promoted the restoration and reconstruction of the education order for the disabled, but also influenced the later formulation of the law on the protection of persons with disabilities and the regulations on the education of disabled persons, and led the development of education for disabled persons to enter a golden period under the background of universal compulsory education.

In the 1980s and 1990s, under the plan to achieve the general goal of popularization of compulsory education in China, the CPC and the state created a edu- 
cational construction model with Chinese characteristics for the disabled. The most representative is the proposal of "learning in regular class (LRC)". Letting students with disabilities enter regular school for education is a breakthrough in the previous single placement model represented by special education schools. As early as 1983, "Interim Provisions on Basic Requirements for Popularization of Primary Education" affirmed the concept of LRC. In 1987, the Golden Key Education Program for Blind Children was a large-scale practical study of LRC, which was chaired by Xu Bai-lun. From 1989 to 1994, practical study was carried out on children with mental retardation, hearing impaired and visual impaired in different provinces and cities, and workshops were held in Shandong, Jiangsu and Heilongiiang for the three handicapped children. At the same time, the integrated education from the Education for All Declaration, Salamanca Declaration provided a theoretical basis for the promotion of implementing LRC in China. Education Regulations for Persons with Disabilities issued by the state council and Trial Measures on Carrying out Work in Classes for Children and Adolescents with Disabilities issued by the former State Education Commission have once again affirmed LRC, and tried to promote it nationwide. The educational development pattern of "take LRC as the main body, take the special education schools and special classes as the backbone" for the disabled has also been established, which has been influential so far. Under the influence of the changes in educational placement, education for the disabled has also undergone profound changes. More and more students with disabilities have been able to receive school education, besides mental retardation, hearing impairment, visual impairment, other disabilities included, such as physical disability, emotional disorder and autism, thus further expanding the range of students with disabilities. The change of practical form often results from the profound change of concept. Students with disabilities can assess to education in regular school, which results from recognizing ideas of disability, reflecting the concept of equality, fairness and acceptance, which is more oriented to the development of potential and integration into society. In 1986, the total number of students with disabilities in school was more than 42,700 , it was more than 295,600 in 1995 , and it increased to more than 398,700 in 2011.

The report of the 17th National Congress of CPC for the first time put forward the concept of "Care More about Special Education". The State has successively promulgated some educational policies, such as Opinions on Further Promoting the Reform and Development of Special Education during the Tenth Five-Year Plan Period, "Plan for the Construction of Special Education Schools in the Central and Western Regions during the" Eleventh Five-Year Plan "(2008-2010)" and so on, by trying to resource inclined to ease the tense situation between supply and demand of education for the disabled in the Midwest resources, further promote the development of narrowing the development gap with the east, ultimately achieve the goal of balanced development. In order to prevent students with students from dropping out of school due to poverty, the $\mathrm{CPC}$ and the state have implemented popularization compulsory education on 
the basis of the policy of "Two exemptions and one supplement", and fully implemented free compulsory education to benefit every student with disabilities, which is an important measure taken by the state to ensure and improve people's livelihood and promote social equity and justice. By 2011, the national average proportion of students with disabilities receiving compulsory education was $72.1 \%, 74.5 \%$ in urban areas and $71.5 \%$ in rural areas. The gap between urban and rural areas has narrowed significantly, and the enrollment rate of students with disabilities in rural areas has increased significantly.

The development of this period enables more and more students with different disability categories to receive school education, even to enter regular primary and secondary schools, in order to realize the value of their lives. At the same time, the tolerance from regular schools and society is becoming stronger and stronger. Under the guarantee of laws and policies, the construction of teachers, funds and courses has been carried out in an orderly way, the education system for the disabled has been rebuilt, and the education for the disabled has been transformed for the better. Among them, LRC with Chinese characteristics is regarded as an important symbol of this period, which effectively promotes the popularization of compulsory education and helps more students with disabilities move from family to school and from school to society (Liu, 2018a).

\subsection{Transforming and Upgrading Education for the Disabled in China (2012-2019)}

Since the 18th National Congress of CPC, the education for the disabled has also entered a new historical journey in China, it explicitly put forward the transition to inclusive education and pursued "fair and quality" education. At the same time, under the comprehensive influence of "completing the building of a moderately prosperous society in all respects "education modernization", "dissemination of equal human rights" and other factors, education for the disabled has highlighted the characteristics of social rights protection. The report of 18 th National Congress of CPC proposed "supporting special education", while the report of the 19th National Congress of CPC further proposed "running special education well". This important goal of high-quality development puts forward higher requirements for the transformation of education for the disabled. Take inclusive education as the main line of educational development and reform, the education for the disabled once again ushered in an important development opportunity.

The establishment of inclusive education policy is an important turning point in the development of education for the disabled in China. Seven departments, including the Ministry of Education, issued Special Education Promotion Plan (2014-2016) in 2014, which explicitly proposed "comprehensively promoting inclusive education" for the first time. The State Council reaffirmed "promoting inclusive education" in the law of Education Regulations for Persons with Disabilities revised in 2017. The inclusive education has been promoted to a new 
height, and has been actively consistent with the development of international education for the disabled. China's education for the disabled has undergone a profound change from related policies to service system. Especially in the process of transforming to inclusive education, teachers have become an important factor. Opinions on Strengthening the Construction of Special Education Teachers released in 2012 put forward "Exploring the Establishment of a Special Education Teacher Certificate System" for the first time, which put forward new requirements for teachers' professional skills. Education Regulations for Persons with Disabilities revised in 2017 also provides two qualifications for teachers specializing in the education for the disabled. All kinds of measures show the tendency of teachers' professionalization, and the improvement of teachers' professional skill will have a positive impact on the quality of education. By 2018, the number of full-time teachers in special education schools had reached more than 58,600, including 1428 teachers with postgraduate qualifications, 39,809 teachers with undergraduate qualifications, 16,418 teachers with junior college qualifications, 987 teachers with senior high school qualifications. In terms of financial support, the central government had allocated 1.08 billion yuan to support the development of education for the disabled by 2015, and the public funding subsidy standard reaches 4000 yuan per student per year. According to the needs of students with disabilities in schools for blind, deaf and mentally retarded, the state has formulated Course Standards for each discipline and compiled teaching materials, which laying a solid foundation for improving the teaching quality of special education schools. By 2018, 665,900 all kinds of students with disabilities were enrolled in schools. There were 58,700 full-time teachers in special education schools nationwide, and $75.65 \%$ of them had received special training.

Looking back over the past 70 years, under the leadership of CPC, education for the disabled has made historic achievements. The enrollment rate of students with disabilities has been constantly rising, the professional skills level of full-time teachers has been greatly improved, and some measures such as funding, resource building and placement, as well as support system construction, have benefited every student with disabilities and their families, which have made a positive impact on the world. At present, we should further implement the 18th, 19th National Congress of CPC on the cause of education for the disabled, upholding and developing education for the disabled with Chinese characteristics, and actively promote educational mode transformation to inclusive education, in the process of completing the building of a moderately prosperous society in all respects, to safeguard the legitimate rights and interests of persons with disabilities, to further boost China's education for the disabled in the world.

\section{Achievements}

\subsection{The Educational Security System Has Been Constantly Improved}

In order to implement "Outline of National Medium and Long-term Education 
Reform and Development Plan (2010-2020)", The First Special Education Promotion Plan (2014-2016) was issued in 2014, which plays an important role in improving the education guarantee level for the disabled. It was successfully completed in 2016. To consolidate the early successes, improve the quality of education for the disabled, the state issued the Second Special Education Enhancement Plan (2017-2020) in 2017, the overall goals and tasks of the education for the disabled are clarified, and specific safeguard measures for the right to education of disabled children are proposed. In 2017, the state revised Education Regulations for Persons with Disabilities that regulates the security system of compulsory education for the disabled.

In order to standardize the teaching work of special education schools and improve the quality of special education, the Ministry of Education promulgated Curriculum Standards for Compulsory Education in Blind Schools, Curriculum Standards for Compulsory Education in deaf schools and Curriculum Standards for Compulsory Education in schools for the mentally handicapped in 2016.

\subsection{Spending on Special Education Increased}

Since the 18th National Congress of CPC, according to "China Education Funds Statistical Yearbook" the per capita expenditure of special education students in China has constant increase, China's special education funding mainly comes from local finance. In 2012, the per capita expenditure of local education and other departments for special education was RMB 45,790.48 yuan, which rose to RMB 49,813.03 yuan, RMB 51,777.83 yuan and RMB 58,922.56 yuan respectively from 2013 to 2015, an increase of $28.68 \%$ compared with 2013. The local government has taken the following measures to subsidize special education funds: 1) set up local special education subsidy. For example, from 2014 to 2017, Guangdong province allocated a total of RMB 1.41 billion yuan of special provincial subsidy, Yunnan province RMB 50 million yuan and Shanxi province RMB 30 million yuan. 2) When implementing the policy of "Two exemptions and one supplement" for compulsory education, special education funds are generally listed separately, and the number of subsidy items is constantly increased and the subsidy standards are raised (Lv, 2017). For example, Beijing and Fujian extended "Two exemptions and one supplement" to "Three exemptions and two supplements" or "three exemptions and one supplements." In 2016, local governments raised the average public fund for students in special education schools for compulsory education to more than 6000 yuan per student, 7800 yuan in Shanghai and 12,000 yuan in Beijing. Students in special education schools in Guangdong were allocated at least 8 - 10 times less than ordinary students. 3) Expand the scope of the recipients of subsidies. The same standards shall be applied to children with disabilities who are learning in regular class, or special education classes in regular school, and receive visiting services in accordance with the average public funds for students in special education schools during the compulsory education period. In addition to the com- 
pulsory education period, a lot of efforts should be made to raise the standard of public funds per student for non-compulsory education. For example, according to the regulations of Xinjiang Uygur Autonomous Region, the public funds per student for students with disabilities in vocational education schools for disabled should be raised by $50 \%$ on the basis of the standard for compulsory education (Liu, 2018b).

\subsection{The Number of Special Education Schools Has Increased and the Conditions for Running Them Have Improved}

Places for the disabled to receive education include not only regular schools, special education schools (classes), and other special education institutions, but also hospitals or families. However, traditional schools are still the main place for education. According to the international development trend and the requirements of China's policies and laws, it is undeniable that inclusive education is the mainstream. However, at the present stage, under the circumstance that regular schools' cannot quickly make the hardware and software environment accommodate students with disabilities, special education schools cannot disappear for the time being and will still play an important role for some time. Moreover, for a long time, the number of special education schools in our country and the educational needs of disabled children gap larger, therefore, it can provide more educational opportunities for students with disabilities through appropriately building more special education schools, which is a positive measure for government to protect the right of receiving education for students with disabilities. In recent years, governments at all levels have vigorously supported the development of special education and actively invested in the construction of special education schools. According to Statistical Communiqué on National Education Development, the number of special education schools was 1853, 1933, 2000, 2053 and 2080 respectively from 2012 to 2016. In 2016, there were an increase of 227 compared to 2012, which was increased by $12.3 \%$. In 2014, China has basically achieved the goal of establishing a special education school independently for each county with a population of more than 300,000 , which is providing more educational opportunities for the disabled. After the promulgation of The First Special Education Promotion Plan (2014-2016), the Ministry of Education and the Ministry of Finance jointly implemented the project to improve the conditions of special education and raised the special education subsidy from RMB 25 million yuan in 2011 to RMB 410 million yuan in 2014, with a total investment of RMB 540 million yuan in the past four years. Besides that, the state has promulgated Guide to the Construction of Special Education Resources Classrooms in Regular Schools and Barrier-free Environment Construction Regulations, which promote the construction of resource classrooms and the improvement of barrier-free facilities in regular schools. Due to the joint efforts of the government and the schools, the Less, broken, old, ugly situation of special education schools has been significantly improved. After receiving special education subsidies, local governments shall equip schools or laboratories 
with rehabilitation training facilities and equipment, in order to ensure the smooth development of special education teaching activities, and "Combining Medicine with Education".

\subsection{The Number of Students Enrolled in Special Education Increased and the Scale of Education Expanded}

From 2012 to 2016, the number of special education students enrolled in compulsory education in China increased rapidly. In 2012, there were 378,800 students in school, but the number fell slightly to 368,100 in 2013 . From 2014 to 2016 , the number rose to $394,800,442,200$ and 491,700 respectively, and the ratio increase to $33.7 \%$ from 2013 to 2016 . By 2016, more than $90 \%$ of children with disabilities were enrolled in compulsory education. The proportion of students receiving special education at the stage of compulsory education refers to the percentage of the total number of students receiving special education at the stage of compulsory education. The index value can reflect the scale of special education in the stage of compulsory education. From 2012 to 2016, the proportion of students enrolled in special education schools at the stage of compulsory education in China was $0.26 \%, 0.27 \%, 0.29 \%, 0.32 \%$ and $0.35 \%$ respectively, showing an increasing trend. This shows that the scale of special education at the stage of compulsory education expands and the enrollment rate of children with disabilities increases.

\subsection{The Proportion of Inclusive Education Increased and the Speed of Development Accelerated}

At the stage of compulsory education, students with disabilities in our country mainly receive education in special education schools, regular classes in ordinary schools and special education classes in ordinary schools. This form is called inclusive education, among which the regular classes in ordinary schools are also called LRC. Inclusive education is a form of education in which students with disabilities and non-disabled students receive education in a common environment. The proportion of the disabled who are learning in regular class or in special education classes attached to ordinary schools can reflect the scale of inclusive education and can also monitor and evaluate the development quality of inclusive education. The proportion of students with disabilities at the compulsory education stage who are learning in regular class or in special education classes attached to ordinary schools (A), the percentage of the total number of students with disabilities in the compulsory education stage (B). From 2012 to 2016, the ratio $\mathrm{A}$ to $\mathrm{B}$ exceeded $50 \%$ each year, and the proportion of inclusive education in junior middle school reached 60.74 percent in 2016.

\subsection{Some Achievements Have Been Made in the Construction of Teachers}

The quantity and quality of teachers determine the quality of education. The shortages of teachers and low degree of specialization in special education have 
been existing for a long time in China. To expedite the construction of special education teachers, Opinions on Further Strengthening the Construction of Special Education Teachers issued by the Ministry of Education and Ministry of Finance, which put forward specific requirements, such as the special education teacher training, training, professional title evaluation, wages and other issues. since then, the number of full-time special education teachers increasing growth, from 2012 to 2016, the number of full-time special education teachers are $437.00,457.00,481.00,503.00$ and 532.00 , the proportion of 2016 is $22 \%$ higher than that of 2012.

The number of full-time teachers who have received specialized training is an indicator of the guarantee of the quality of education, which can reflect the degree of specialization of special education teachers. Special education teachers' professional training opportunities have been increasing for recent 5 years. The full-time teachers who received special education professional training have been more than $60 \%$ since 2013, it suggesting that special education degree of specialization of teachers and teachers' professional quality has been improving.

\section{Existing Problems}

\subsection{The Level of Education Development at the Stage of Compulsory Education Is Unbalanced}

Education for the disabled is developing unbalanced between urban and rural areas, and among regions. The ratio of special education students to special education teachers at the stage of compulsory education is given. The teacher-to-student ratio refers to the average number of students taught by each full-time teacher in a certain school year. This indicator can be used to reflect the adequacy of the number of teachers, which is often used as an alternative indicator for the quality of education, usually 4 to 6 . The higher the teacher-student ratio is, the more students each teacher teaches on average, the lower the education quality is; the smaller the teacher-student ratio, the lower the average number of students per teacher, the higher the quality of education is. In 2016, the average student-teacher ratio of 31 provinces in China was 10.4, the minimum value was 4.41 in Liaoning province, and the maximum value was 23.1 in Qinghai province, the difference between them is almost 5 times, it shows that regional education quality varies widely.

\subsection{The Quality of Compulsory Education Needs to Be Improved}

The quality of education for the disabled is determined by its level of support from the state. Take LRC for example, there are many difficulties in the academic evaluation and potential improvement of students with disabilities who are learning in regular due to the lack of special education professional ability of teachers in ordinary schools. Some students with LRC are often in the "free state" when take part in teaching activities, it is difficult to really integrate into their peers, resulting in poor educational effect. Although some ordinary schools 
have set up special education resource classrooms with a complete set of facilities, however, many teaching instruments and equipment are idle due to the lack of professional staff.

In some underdeveloped economy areas, a number of teachers have no special education background in the new rural special education school, it is less relatively opportunities for them to participate in professional training, which results in the teachers' lack of special education experience, so not only the lesson plan, but also their teaching activities is low professionalism or poor pertinence. Some schools "Go through the motions" instead of really classroom teaching, which results in low education quality, and the right to education of children with severe and multiple disabilities is poorly protected.

The Regulations on Education for Persons with Disabilities stipulates that on-site services are provided for children with disabilities who are unable to study in school. However, due to the imperfect system including teachers who providing on-site services, the personnel, teaching methods, education content and other provisions lag behind, the number of students with disabilities who receiving on-site services is limited (Fang, 2014). In 2015, some experts pointed out that children with autism, cerebral palsy and multiple disabilities in China were suffering from serious educational problems in " $<$ Outline of the National Medium and Long-term Education Reform and Development Plan> Special Evaluation Report on Special Education for Mid-term Assessments".

\section{Conclusion}

Since the 18th National Congress of CPC, the state has attached great importance to the education for the disabled. It should be noted that these educational achievements for the disabled have benefited from the efforts made by governments, schools and social organizations. We will consolidate the enrollment rate of students with disabilities in compulsory education and improve the quality of education. On the one hand, we should improve the education security system for students with severe and multiple disabilities, implement and improve the system of on-site services, and consolidate the enrollment rate of students with disabilities on receiving compulsory education. On the other hand, the state should continue to increase the emphasis on teachers engaged in special education in terms of teacher establishment, salary, and evaluation of positions (titles) to attract more outstanding talents to special education; Let special education schools take charge of special education teacher training and teaching research, carry out roving guidance, performance evaluation, and consultation on special education and teaching, and improve teaching quality.

\section{Conflicts of Interest}

The authors declare no conflicts of interest regarding the publication of this paper. 


\section{References}

Fang, J.-M. (2014). Striving to Build a Lifelong Education System for the Disabled. China Special Education, 2, 19-20.

Liu, P. (2018a). The Development Process of Compulsory Education for the Disabled in China (p. 8). Report on the Development of Human Rights in China. Beijing: Social Science Literature Press.

Liu, P. (2018b). Research on the Development Process of the Educational Status of the Children with Disabilities in China. Research on Disabled People, No. 4, 50-57.

Lv, C.-M. (2017). A Review of Research on Special Education Funds in China in Recent Years. Journal of Suihua University, 37, 124-127. 